\title{
Application Research of Blended Teaching based on Duifene Teaching Platform: Modules on Construction Project Management
}

\begin{abstract}
Jingjing Sun*
Chongqing Energy Vocational College, Chongqing 402260, China

Funding: Chongqing Higher Education Teaching Reform Research Project Application Research of Blending Teaching based on Duifene Teaching Platform 203195. Chongqing Higher Vocational and Technical Education Research Association. Mobile phones in the classroom: a practical study on building a 1:1 digital teaching model GY201084.

Abstract: The Duifene teaching platform is a product of various teaching methods, which greatly improves the traditional teaching method. This article introduces the function and characteristics of a blended teaching platform as well as its application for histology and embryology modules. In addition, the advantages and disadvantages of blended teaching method is also discussed. The application of this teaching platform for Construction Project Management modules encourages students to be more enthusiastic and interested toward learning. This allows a more convenient and rapid teacher-student and studentstudent interaction thereby improving the teaching and learning experiences.
\end{abstract}

Keywords: Duifene teaching platform; Construction Project Management; Blended teaching

Publication date: May, 2021; Publication online: 31 May, 2021

*Corresponding author: Jingjing Sun, jiangwei001vip@126.com

\section{Introduction}

The course modules for Project Management in Construction Engineering are wide-ranging and theory-based with a trivial structure. This makes it difficult to distinguish and remember the modules, causing a lack of initiative and interest to study among the students if the traditional teaching mode is used. To overcome the poor learning results, a reform of traditional teaching method is needed. Therefore, with an improved quality of teaching, students' attitude will be changed toward independent learning instead of dependent learning. With the recent advancement of information technology, a series of online teaching platforms such as "Pair of Points Easy," "Rain Classroom" and "Super Star Learning Pass" have been developed. The author has chosen to apply the blended teaching method in multiple platforms, thus comparing it with the traditional teaching method. As a result, the blended teaching method has increased student's enthusiasm toward learning and helped teachers achieved good outcomes.

\section{Rationale for Selecting Duifene Teaching Platform and its Teaching Method}

Duifene is the official teaching platform which uses the Presentation Assimilation Discussion (PAD), a new and applicable teaching method. The PAD teaching method can be used in various classrooms of learning. This platform has three distinctive features. Firstly, it is simple and convenient to use, and takes up very little space as there is no need to download any software, plug-ins, or mobile apps. Secondly, the platform's display is simple and clear, and the modules are fully functional. Also, the platform now has 18 functional modules consisting of interactive live streaming, student management, course resources, group discussions and online exercises which fully cover the functions required for teaching and student management. Thirdly, it is 
easy to achieve the management of students and complete the evaluation of the teaching process. As the platform is built with the help of the WeChat public account, this makes it easy to contact and communicate with students, as well as facilitate interaction, discussion, and Q\&A with students before and after classes.

The distinguishing feature of PAD is that the lecture time is divided into two halves. The first half is used for the "lecture-style classroom" method, whereby the teacher teaches the key points and equations in class, thus making students focus on the lecture, while the second half is used for the "group discussion-style classroom" method, whereby students discuss and answer questions in class. Therefore, PAD aims to encourage interest in learning and improve learning efficiency through presentation, assimilation, and discussion, as shown in Figure 1. The teaching method is based on the "Pair of Points Easy" platform, which is mainly designed considering five aspects: preparation before class, teaching arrangement during the lesson, organization after class, formative evaluation, and summarization of teaching outcomes considering the improvement and optimization of teaching methods. The aim of using the "Pair of Points Easy" platform as a foundation is to highlight the leading role of teachers and the main role of students in the teaching process, integrate the advantages of traditional classroom teaching methods and online courses, highlight the development of independent learning and thinking ability among students, and encourage group studies.

\section{Pedagogical Implementations based on Duifene Platform}

\subsection{Preparation for class}

Before starting a lesson, the students should have a thorough understanding of the teaching module and learning targets as a preparation for the lesson. The teaching module mainly refers to the problem and analysis of the teaching objectives, syllabus, teaching schedule, chapter key points and difficult theories. Besides that, the preparation of understanding the learning target mainly refers to asking information from senior students who have taken the modules previously. Before the lesson, teachers create a new semester on the Duifene platform where they add the class in the new semester. Then, generate a class QR code and invite the class to scan the code to join and make a note in the form of student number + name, to facilitate communication in class. Furthermore, teachers are required to assess the target audience and prepare teaching materials in accordance with their professional characteristics before teaching. In addition, teachers are also required to log onto the "Pair of Points Easy" platform before the lesson to complete the preparation of teaching materials, including posting introductory videos, uploading syllabuses, teaching schedules, courseware, chapter frameworks, lecture points, pre-tests, and uploading extended resources such as animations and literature. The tutorial video is a brief overview of the basic content and key points of this lecture. It is uploaded in the course resource area of the Duifene platform in the form of a recorded microlecture video. In the course resource area, the courseware and lectures synchronized with the teaching are also uploaded at the same time. Moreover, essentials, animations, and expanded literature are easy to learn and preview with this platform. Pre-lesson teaching resources should not only be informative and easy to understand, but also highly relevant to the content of the lecture. Uploading redundant and ineffective resources not only interferes with students' grasp of key and difficult theories, but also increases the learning burden and reduces interest in learning. The pretest is to test the students' knowledge level, prestudy effect and self-learning ability, as well as to group them according to their performance and ability and select group leaders to facilitate tiered teaching.

\subsection{In-class teaching arrangements}

The teaching time is divided into two, where half the time spent on the lecturer's teaching and half on organizing group discussions with students. In the 
pre-class preparation stage, students have already studied the micro-lecture videos, lecture points and other relevant materials before class, so the teacher's classroom live broadcast can be conducted directly in the offline live module of the platform. After the teacher has finished the lecture, they will release one to three questions on the key points and equations in the classroom in the form of an accompanying test.

Contrarily, the second half of the class will be used to organize group discussions with the students. The teacher will need to communicate with the students and the class leader before the class to complete the grouping to ensure that the members of each group are evenly distributed according to their grades and personalities. This is to ensure students with good grades would lead students with average grades and students with active personalities would lead students with introverted personalities. The group leader is responsible for leading the discussion and the note taker is responsible for recording each student's ideas or answers. At the end, the answers will be compiled and submitted as a group. Each student's interaction is automatically recorded on the platform and after the group discussion is completed, the teacher and students discuss with each other. In this process, student's ability of independent learning and access to information is improved through the process of finding out questions, consulting information, answering questions, and summarizing. This lays the foundation for good communication between students and teachers.

\subsection{After-school organization}

After the lesson, the teacher will post the chapter exercises and students are required to complete and submit answers to the exercises within the time limit. In addition, the micro-lesson summary video will be posted on the platform, allowing the students to watch the micro-lesson videos after class and draw a chapter mind map and upload it. This helps the students to develop their subject knowledge. Furthermore, teachers can publish after-class discussion topics in the topic discussion section of the platform, so that students and teachers can communicate and interact with each other on certain key points or module-related issues, as well as share and answer problems encountered in learning, which not only broadens the communication channel between teachers and students, but also achieves the purpose of revision, consolidation, and knowledge expansion.

\section{"Presentation Assimilation Discussion"}

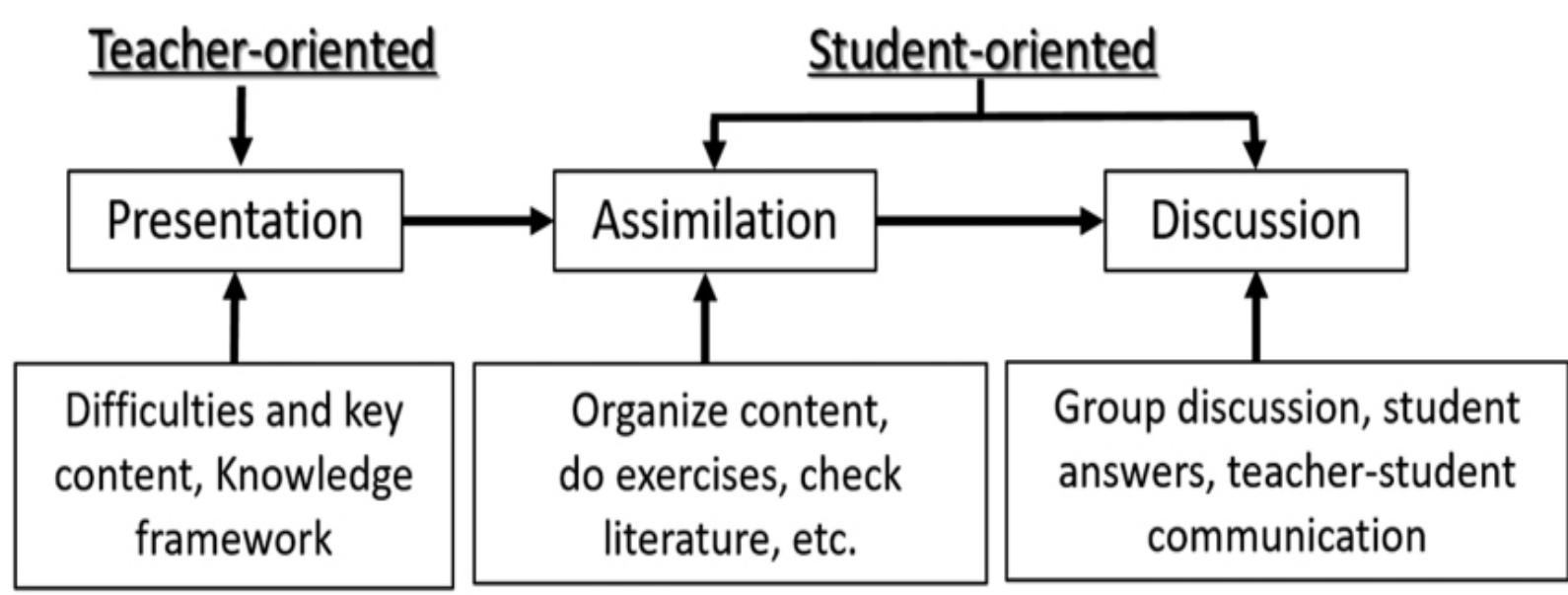

Figure 1. Teaching process of "Presentation Assimilation Discussion" 


\subsection{Formative evaluation}

To form a quality education system based on the development of independent learning skills, challenges in improving students' learning initiatives, guiding students to complete independent learning outside the classroom, and ensuring discipline in students during live classes without strict supervision need to be addressed. Therefore, the scientific formative assessment can help to solve these challenges in online teaching. Formative assessment is an important teaching tool to monitor the teaching process and ensure the effectiveness of teaching. It is a four-stage process of "evaluation, feedback, correction and improvement," which allows timely revision and optimization of teaching activities. It is a powerful platform for student management, which not only provides real-time student learning monitoring data, but also allows statistical analysis of the data in the backend system. Additionally, it is an important aid for teachers in the teaching department to keep track of students' progress in learning a particular subject and completing formative assessments.

\section{Teaching Effectiveness and Potentials}

At the end of the semester, it is analyzed that the effectiveness of the online teaching platform based on the concept of the "Pair of Points Easy" platform through formative evaluation, analysis of mid-term and final exam papers, two student questionnaires at the middle and end of the teaching periods, and student interviews. Thus, the findings are that the student's participation in online teaching is high; $86 \%$ of the students were able to study and prepare the materials before the lesson, $90 \%$ of the students participated in group discussions during the lesson, and $89 \%$ of the students communicated with each other and with the teacher after the lesson. The teaching effect is better than the single-method traditional classroom. The results of the final examination paper analysis showed that the average performance of students who received online teaching on the "Pair of Points Easy" platform was higher than the traditional classroom teaching and the pass rate increased from $89 \%$ to
$93 \%$, given that the assessment points, difficulty level and coverage of the questions were similar. In addition, students' satisfaction with the learning outcomes has improved. The results of the questionnaire survey showed that $98 \%$ of students thought that learning before class had significantly improved their ability to learn in the classroom. Also, 95\% of the students thought that effective teacher-student and peer communication was conducive to a deeper understanding of knowledge, and $96 \%$ of students thought that this method of teaching had effectively increased their enthusiasm for learning as well as improved their own learning initiative and satisfaction. This teaching method shows that under the goal of cultivating independent learning abilities and encouraging innovative faculties, new teaching and learning style should be introduced and adopted in the advent of internet era. Faculty training needs to place emphasis on education innovation and motivation of students for a two-way synergistic development based on network communication technology. These changes are bound to revolutionize the traditional teaching methods. The online teaching mode of the "Pair of Points Easy" platform is a supplement to the traditional physical classroom lesson. It is a new education method based on the overall understanding of the development of our traditional education and new education policies as well as the development of online teaching advantages. Soon, we will also use the internet to promote the reform of higher medical education teaching to improve the overall effectiveness and quality of teaching.

\section{Disclosure statement}

The author declares no conflict of interest.

\section{References}

[1]Jiang, P.T., Guo, N., Hu, Z.F., et al.(2019). Proper Use of Medical Immunology Teaching Recourses in Internet era. Chinese Journal of Immunology,35( 5):613-615.

[2]Zhang, X.X(2014). PAD Class: A New Attempt 
in University Leaching Reform. Fudan Education Forum,12( 5) :5-40.

[3]Liu, M.Q(2016). The Teaching Effect on Presentation Assimilation Dicussion ( PAD) Class in Biology. Microbiology China,43( 4):730-734.

[4]Wang, N(2020). Application Research in Online Teaching of "Medical Immunology" based on
"Duifene" Platform. Chinese Journal of Immunology,35( 4): 2218 -2222.

[5]Wang, Y. Design and Application of PAD Classroom Teaching Process Using Duifene Teaching Platform[D]. Guangdong Polytechnic Normal University. 